\title{
Secret Econometric Business: Watching FuelWatch and the ACCC
}

\author{
Sinclair Davidson ${ }^{1}$
}

\begin{abstract}
This paper appraises the econometric study of Western Australia's FuelWatch scheme that the ACCC has used to advocate to the Federal Government the petrol price regulation scheme known as 'Fuel Watch'. It is argued that the ACCC's econometric analysis is fundamentally flawed.
\end{abstract}

\section{Introduction}

The Australian people are being enticed towards a FuelWatch scheme because you have told them it will bring down the price of petrol. You base that on the premise of an econometric model. The model was devised, tabulated and constructed in your office and nobody but the people inside your office have had anything to do with it.

Senator Barnaby Joyce, Senate Estimates, 5 June 2008.

This paper argues that the national FuelWatch scheme has not been adequately analysed by the Australian Competition and Consumer Commission (ACCC). The econometric analysis that has been undertaken is incomplete, the upshot being that the ACCC has favoured a scheme to fix prices, retard competition and thereby harm consumers, on the basis of analysis and information that either does not exist, or is not in the public domain.

\section{Background}

A 'FuelWatch' scheme was introduced in Western Australia in January 2001. This followed the October 2000 recommendations of a WA parliamentary select committee, in its report Getting a Fair Deal for Western Australian Motorists. The purpose of the scheme has been to provide certainty to consumers as to petrol prices for a fixed period of time. In practice, WA service stations have been required to notify FuelWatch of their prices for the next day. On the following day, beginning at 6am, the service station fuel prices are fixed for 24

\footnotetext{
${ }^{1}$ School of Economics, Finance and Marketing, RMIT University, and the Institute of Public Affairs, sinclair.davidson@rmit.edu.au .This paper is revised from a submission to the Senate Economics Committee Inquiry into the Fuel Watch legislation. I would like to thank Informed Sources for providing the data used in the analysis. The views expressed here do not necessarily reflect the views and opinions of Informed Sources. I would like to thank Chris Berg, Kate Herbert, an anonymous referee, and William Coleman for comments and suggestions that have substantially improved the paper.
} 
hours - this is known as the 24-hour rule. The 24-hour rule was amended to close a loophole in August 2001.

The WA FuelWatch scheme has been investigated on a number of occasions. The ACCC argued in its December 2002 Terminal gate pricing arrangements in Australia and other fuel pricing arrangements in Western Australia that it is hard to conclude that the Western Australian fuel pricing arrangements have been successful to date' (p.47). The ACCC also expressed concerns that the WA FuelWatch scheme had had a detrimental effect on competition. In October 2006, the ACCC was able to advise the Senate that additional investigations into the WA FuelWatch scheme had occurred (Senate Estimates Hansard, 19 October 2006: E20). These reports included a May 2005 Northern Territory report, the 2005 National Competition Council assessment report, and an April 2006 Queensland government report. Graeme Samuel approvingly quoted from the National Competition Council report that the Council 'considers that Western Australia is yet to conclusively demonstrate that its petrol pricing restrictions provide a net public benefit, and [the Council's] concerns were heightened by fines imposed on a retailer in July 2005 for lowering price(s). Such an outcome does not appear to promote competition and consumer interests' (Ibid: E21).

The ACCC CEO Brian Cassidy also had his doubts - as these doubts are important for the later argument, they are detailed in full:

We are doubtful, at the very least, about just what impact the Western Australian arrangements have had on price levels in Western Australia. The arrangements came into place in 2001. If you compare Perth prices against Sydney and Melbourne, between 2001 and 2003-04, there was a marginal improvement in Perth prices relative to Sydney prices and there was an actual deterioration in Perth prices relative to Melbourne prices. Around 2003-04, two things happened. Firstly, Coles and the joint venture Woolworths-Caltex sites started to enter the Western Australian market ... Secondly, Western Australia for some time has had reasonably restrictive fuel standards. Around 2003-04, the Commonwealth introduced national fuel standards, which are not as restrictive as the Western Australian standards but they nonetheless came into force, although the more restrictive Western Australian standards still apply in Western Australia. So it meant there was a levelling up to some extent, if you like, in the price impact of the fuel standards between Western Australia and other states.

If you look at that price comparison I was talking about it is interesting to note that it is really only after 2003-04 that there has been some improvement in Perth prices as against both Sydney and Melbourne prices. Given the Western Australian arrangements have been in place since 2001, you are then left to wonder whether that improvement, which 
has occurred from about 2003-04 onwards, is a product of the Western Australian arrangements or whether it is a product of these other factors. If you say it is a product of the Western Australian arrangements, then the next question is why did it take two or three years for those arrangements to actually start to impact on the price relativities between, say, Perth and Sydney and Melbourne? (Ibid: E19-E20).

The doubts that the ACCC harboured about the WA FuelWatch scheme related to whether the policy actually had led to decreased prices in isolation of the confounding effects of the entry of Coles and Woolworths into the market along with a change in fuel standards. These are serious and legitimate doubts about the efficacy of the FuelWatch scheme. The ACCC had long had doubts about whether the FuelWatch scheme actually reduced prices and had undertaken extensive analysis of petrol pricing in its 2002 report (the analysis ran for several pages but did not include any econometric or regression analysis). It is clear that as late as October 2006 the ACCC was not in favour of the WA FuelWatch scheme being extended to other parts of Australia.

In December 2007, the ACCC released Petrol Prices and Australian Consumers, its report into petrol pricing in Australia. While the ACCC expressed some concern about transparency in retail petrol markets, it did indicate that 'there is a significant degree of price competition at the retail level' (ACCC 2007: 15), and 'the existence of price cycles does not provide any evidence of a lack of retail competition' (Ibid: 16). Importantly, the ACCC also indicated 'that in the time available it was not possible to fully review all the options with regard to their administrative implications, effects on competition or their likelihood of delivering the objective of increased price transparency' (Ibid: 18). Nowhere in the 2007 report did the ACCC actually recommend a national FuelWatch scheme be adopted. ${ }^{2}$ However, the report did include an Appendix (Appendix S) that contained an econometric analysis of the WA FuelWatch scheme that implied, according to the ACCC, that 'there has been some reduction in average price margins [in Perth] relative to the eastern capitals in the time following the introduction of FuelWatch' (ACCC 2007: 257; emphasis added).

Within six months of the release of the 2007 report, the ACCC had reversed its previous position that the Western Australian FuelWatch scheme was not worth extending to other parts of Australia. On 4 June 2008, a Treasury official told the Senate Estimates Committee: 'In discussions with the government, the chairman of the ACCC recommended that we should introduce a Fuelwatch

\footnotetext{
2 At the Senate estimates, Graeme Samuel commented: 'If the commissioners that sat on that inquiry had found through that econometric modelling that Perth motorists had suffered harm as a result of the introduction of FuelWatch, we would never have recommended it to the Australian government in our report ' (Senate Estimates Hansard, 5 June 2008: E16; emphasis added). The ACCC did recommend FuelWatch to the Australian government; but not in its 2007 report 'Petrol Prices and Australian Consumers'.
} 
scheme' (Senate Estimates Hansard, 4 June 2008: E85). When challenged on this reversal, Graeme Samuel paraphrased John Maynard Keynes: 'When I find evidence that I was wrong, I change my mind. What would you do?' (Senate Estimates Hansard, 5 June 2008: E57). But what might be that evidence? Not economic modelling: when asked by Senator Helen Coonan as to whether any economic modelling had been done on the notion of consumer empowerment, Graeme Samuel answered, 'No' (Ibid: E65). However, econometric analysis had been widely cited as demonstrating that the FuelWatch scheme has led to lower prices in Western Australia. At Senate estimates, Senator Barnaby Joyce put it to Brian Cassidy that 'The whole premise of FuelWatch is based on this econometric analysis. That is why it is the crux of our questioning.' Cassidy replied, 'Yes' (Ibid: E42). It seems quite clear that the federal government relied on the ACCC when making the decision to implement a national FuelWatch scheme and, in particular, relied on the fact that the ACCC had undertaken a rigorous econometric analysis. ${ }^{3}$

\section{But what econometric analysis?}

On 29 May 2008, the ACCC released a document containing details of 'further FuelWatch econometric analysis'. This document reports the results of an unnamed econometric testing procedure, and does not report any of the diagnostic statistics such as standard errors or p-values that one might expect in any econometric analysis. The ACCC provides a description of its analysis 'known as endogenous selection of structural break points' (ACCC 2008: 3). This analysis apparently identified a number of dates of interest (March 2000, May 2000, February 2004 and September 2005). It is not clear, however, what historical significance attached to these dates. This later ACCC document also moved the policy goalposts by claiming that 'there is no evidence that the introduction of Fuelwatch in Western Australia led to any increase in prices and it appears to have resulted in a small price decrease overall' (Ibid: 4). Of course, the claim being made about FuelWatch was that it would reduce petrol prices, not increase them. When asked about this analysis at the Senate estimates committee one week later, the ACCC still did not name the econometric test that had actually been performed, but did reveal that all the structural breaks were significant at the five per cent level.

In short, the only solid empirical evidence the ACCC has to support its recommendation to implement a national FuelWatch scheme is located in Appendix S of the Petrol Prices and Australian Consumers report.

\footnotetext{
${ }^{3}$ Furthermore, the Minister for Competition Policy and Consumer Affairs, Chris Bowen, told the Parliament on 28 May 2008, 'The ACCC recommended that more work be done on FuelWatch. I understand that the government had had the benefit of that analysis and that process and that the opposition has not ... The chairman of the ACCC is more than happy to work them through the analysis that the ACCC has done, work them through the econometric analysis and work them through the proposals' (Hansard 28 May 2008: 52).
} 


\section{Appendix S of the ACCC's Petrol Prices and Australian Consumers report}

For the Appendix S analysis the ACCC collected average weekly, average monthly and weekly minimum data for the period 1 August 1998 to 8 June 2007. ${ }^{4}$ They then calculated the following Price Margin (PM) measure:

$\mathrm{PM}=(\mathrm{RP}-\mathrm{MP} 95-\mathrm{NT}-\mathrm{FQP})$ Perth $-(\mathrm{RP}-\mathrm{MP} 95-\mathrm{NT}-\mathrm{FQP})$ Average of eastern capitals

where

$\mathrm{RP}=$ retail price

MP95 = Mogas95 price lagged by one week

NT $=$ net tax

$\mathrm{FQP}=$ fuel quality premium.

The ACCC defend this measure on the basis that it removes factors that are beyond the control of FuelWatch, Mogas95 price being the base supply price of petrol (the average daily price of unleaded petrol from refineries traded in Singapore) lagged one week. Yet it is difficult to understand why this figure has been subtracted from the retail price, as it is likely to be constant across Australia. Unfortunately, the ACCC analysis gives no indication as to whether this figure does vary across the various states. It is also unfortunate that the ACCC did not take transport costs into account. These costs are likely to vary across states, and their omission is likely to have biased the results. Similarly, it is not clear whether the net taxes figure varies across states. The mandated fuel quality does vary across states, but the ACCC analysis gives no indication as to what those figures or variations might be. Brian Cassidy told the Senate that the fuel-quality standards were higher in WA relative to the other states, and this adjustment is appropriate for that reason. Overall, however, the measure of interest is not transparent.

The ACCC analysis then investigates whether the data exhibit a structural change after the introduction of FuelWatch. It appears that the ACCC estimated the following equation:

$$
\mathrm{PM}_{\mathrm{t}}=\alpha+\beta \mathrm{FW}_{\mathrm{t}}+\varepsilon_{\mathrm{t}}
$$

where

$\alpha=$ constant representing the average Price Margin before the FuelWatch scheme was introduced

$\beta=$ the average impact of the FuelWatch scheme

$\mathrm{FW}_{\mathrm{t}}$ is a dummy variable $=1$ after 2 January 2001 and $=0$ before 2 January 2001.

\footnotetext{
4 The ACCC did not provide any summary data or description of that data.
} 
The ACCC estimates three versions of the equation, one for each of the three time series versions of Price Margin. They report the results in their Table S2 (reproduced below from ACCC 2007 report: 377).

Table S2 Structural break test ${ }^{\grave{a}}$ for relative price margin, cpl, August 1998 to June 2007

\begin{tabular}{lcc}
\hline Series & Average (August 1998 to December 2000) & Average (January 2001 to June 2007) \\
\hline Weekly average & $0.83(0.002)$ & $-1.92(0.000)$ \\
Monthly average & $0.88(0.001)$ & $-1.86(0.000)$ \\
Weekly minimum & $0.30(0.277)$ & $-0.90(0.003)$ \\
\hline & Coefficient given with p-value in brackets. Diagnostic testing indicated serial correlation so Newey West standard errors used. \\
Source: ACCC estimates &
\end{tabular}

To understand this table, look at the "weekly average" row. The number 0.83 indicates that there was, on average, a 0.83 cent per litre (cpl) difference between the Perth Price Margin and that of the average of the eastern capitals before FuelWatch was introduced. This figure corresponds to the -term in the equation (2). The number in parenthesis (0.002) indicates that the $0.83 \mathrm{cpl}$ difference is statistically significantly different from zero. The figure -1.92 represents the impact FuelWatch had on the Price Margin; this is the $\beta$-term in equation (2). This implies that the Perth net price fell, on average, by $1.92 \mathrm{cpl}$ relative to the average of the eastern capitals following the introduction of FuelWatch. The number in parenthesis $(0.000)$ indicates that the $-1.92 \mathrm{cpl}$ difference is statistically significantly different from zero.

This analysis is consistent with the claim that the WA FuelWatch scheme led to lower prices following its introduction in 2001. Although the ACCC does discuss some important caveats to this analysis, it does not report whether it considered any other factors that could have resulted in a change in relative prices between Perth and the eastern capitals. As shown above, the ACCC had previously suspected that the entry of Coles into the WA market had had an effect, whereas FuelWatch did not. Brian Cassidy told Senate estimates: 'It is interesting that in the econometric work that was done for our report last year we did find a price effect as a result of the Coles entry, but (a) it was relatively small, and (b) it was less than the price effect of FuelWatch' (Senate Estimates, 5 June 2008: E7). But it is especially difficult to understand why this particular analysis was not included in Appendix S - this is the most obvious alternative explanation for what had happened in WA, yet they clearly did not see the need to report this analysis in Appendix S.

\section{The Data Dispute and Peer Review}

The ACCC declined to make its Appendix S data available for analysis by others, and provided a somewhat confused explanation for its refusal to do so. There are two points worth stressing here. First, Graeme Samuel suggested that the 
data belongs solely to Informed Sources, and that independent analysts could replicate the ACCC analysis if Informed Sources chose to release the data. ${ }^{5}$ But that argument is not consistent with evidence given by other ACCC officials, and I show below that the ACCC data sets do not belong to Informed Sources. Second, the ACCC's statements regarding peer review might leave an observer wondering if it ever had any intention of allowing its analysis to be peer reviewed.

Graeme Samuel told the Senate:

We were asked by Informed Sources the other day whether the data we had could be made available. We advised Informed Sources that, of course, it is their proprietary data, they can make it available to whoever they want, whenever they want, in whatever form they want and the parties to whom they make that data available can then do whatever they like with it. That is not under our control. That is a matter for Informed Sources. It is their data. ${ }^{6}$

(Senate Estimates Hansard, 5 June 2008: E32; emphasis added)

Informed Sources, however, do not own the entire dataset that the ACCC use. Informed Sources only own the price series. In other words, it is not possible for Informed Sources to make the ACCC data set available to the public. This was acknowledged by another ACCC officer: 'The other adjustment we made was for fuel premiums. That is not available to people. That is also confidential data so people would need to go [to] the refineries to get that. We could not release that without the refineries' agreement. That is their data' (Ibid: E34). In other words, the data do not all belong to Informed Sources. ${ }^{7}$

It looks almost as if the ACCC has worked hard to avoid any peer review, especially relating to any data release. As an ACCC officer told the Senate:

I might add that a peer review would normally involve the peer getting access to the original data and running their own tests on it. That is what a peer review would normally involve. We have provided the results for people to do that. The tests that we ran are known to other econometricians. As Treasury has also verified, they are standard. As

\footnotetext{
${ }^{5}$ Informed Sources (www.informedsources.com) is a market research company that collects, inter alia, data on petrol prices.

${ }^{6}$ Informed Sources did release their data to some individuals and not others. At the Senate Inquiry into FuelWatch in Melbourne, Graeme Samuel described this as being 'offensive' (Senate Hansard, 7 August 2008: E7).

7 This became clear when the ACCC gave evidence to the Senate Inquiry into FuelWatch in Melbourne. Stephen King told the Senate: 'Professor Davidson has the Informed Sources data, but, as I understand, in his analysis did not adjust that data for taxes and subsidies and did not adjust that data for fuel premium, fuel quality standard-premium' (emphasis added) (Senate Hansard, 7 August 2008: E10).
} 
long as the owners of the data are prepared to release it, people can go in and apply the standard tests.

(Ibid: E33; emphasis added). The very next speaker in Hansard is Graeme Samuel saying: 'If Informed Sources wants to release the data that they gave to us to anyone else - they gave it to us under subpoena - they are entirely free to do so.' Graeme Samuel adds to this perspective:

... I am not in a position to be able to say that we would make our data and our methodology available to anyone out in the public arena. We are not prepared to make all this available for any economic modeller or any economic student to simply go through and then to engage the already heavily worked staff of the ACCC in debate on these issues.

(Ibid: E42, emphasis added). Notice that what was Informed Sources data is now the ACCCs data. The subsequent exchange between Senator Barnaby Joyce and Graeme Samuel is worth quoting in full.

Senator Joyce: Let us cut to the chase: what you are saying is that you will not allow independent reviewing of that modelling work?

Mr Samuel: I would have thought that I did not say that. I said that Treasury had undertaken its own robust analysis. But if there is an economic consulting firm that wants to do its own analysis of the impact of FuelWatch in Perth then they can approach Informed Sources. Not that it is our right to do so anyhow, but we have said to Informed Sources, 'You are absolutely free to make whatever data you want available to whomever you want on whatever terms and conditions you want to make it, so they are entitled to do their own research and use whatever test they want to use and whatever methodology they want to use. I am sure that there are some economic consulting firms that will find someone prepared to give them a brief to do that.

The extent of Treasury's 'own robust analysis' had been revealed to the Senate Estimates Committee the previous day when Senator Helen Coonan asked for a description of the review that the Treasury had actually done as part of their 'robust analysis'. A Treasury official replied:

The ACCC sent us the data set that they created to be used as part of the econometric analysis. That was in the form of a starter software that allows you to run these programs. I, myself, actually use Eview[s] and was not able to do that so, ..., I referred to one of my colleagues ... who has the expertise of this software and I asked him to basically run exactly the same regressional(sic) equation that was provided in the ACCC's analysis and to check to make sure the results were identical and that it provided statistically significant results. He confirmed all of that" 
(Senate Estimates Hansard, 4 June 2008: E90-91; emphasis added).

In other words, the Treasury's 'robust analysis' consisted of them re-estimating the ACCC model, using the ACCC data, and using the same software to determine the same result. Treasury, however, did not undertake a similar robust analysis of the 29 May press release. They told the Senate Estimates committee that they received that analysis on 29 May - the day it was released to the public at large.

\section{Replication}

Given that the ACCC would not release its own dataset for analysis, Informed Sources provided its petrol price dataset, including average daily (simple average across the sites monitored by Informed Sources), average weekly (simple average of the average daily prices for that week) and average monthly (simple average of the daily prices for that month) prices for Perth, Adelaide, Melbourne, Sydney and Brisbane, to selected academics and consultancy groups. The selected academics included Don Harding of La Trobe University and me. This is the same data that Informed Sources had provided to the ACCC. That dataset does not include the Fuel Quality Premia, Mogas95 prices or the net taxes used by the ACCC in its analysis. I was able to calculate a similar measure to the ACCC measure but I was not able to replicate the ACCC measure. I calculate a Relative Price measure where the Average of the eastern state capital average prices is subtracted from the Perth average price. In order to confirm the ACCC analysis I estimate the following equation:

$$
\text { Relative Price }_{\mathrm{t}}=\alpha+\beta_{1} \mathrm{FW}_{\mathrm{t}}+\varepsilon_{\mathrm{t}}
$$

where

Relative Price $_{\mathrm{t}}=$ Average Price $_{\text {Perth }}-$ Average Price $_{\text {Eastern Capitals }}$ at time $\mathrm{t}$ $\alpha=$ a constant representing the average Relative Price before the FuelWatch scheme was introduced $\beta_{1}=$ the average impact of the FuelWatch scheme $\mathrm{FW}_{\mathrm{t}}$ is a dummy variable $=1$ after 2 January 2001 and $=0$ before 2 January 2001.

The table below shows the result of this exercise.

Table 1: FuelWatch structural break test for relative prices (August 1998-June 2007)

\begin{tabular}{llllll}
\hline & \multicolumn{2}{c}{ Constant } & \multicolumn{2}{c}{ FuelWatch } & Adj-R $^{2}$ \\
\hline Weekly Average & 3.0246 & $(0.0000)$ & -0.8529 & $(0.0002)$ & 0.0430 \\
Monthly Average & 3.0207 & $(0.0000)$ & -0.8515 & $(0.0077)$ & 0.0763 \\
\hline
\end{tabular}

Numbers in parenthesis are p-values. Standard errors are Newey-West corrected. 
The results are consistent with the original ACCC analysis. Before the introduction of Fuelwatch, it appears that the petrol price in Perth was about $3 \mathrm{cpl}$ higher than in the eastern capitals. After the introduction of Fuelwatch, it appears that petrol prices in Perth fell by $0.85 \mathrm{cpl}$ relative to the eastern capitals.

The ACCC argue that: "Of potentially greater concern is the possibility that something else entirely has driven the improvement in the relative price margin." The ACCC, however, did not investigate the most obvious other factor - the entry of Coles into the WA fuel market in March 2004. Using the Informed Sources dataset, I investigated that possibility.

I calculate the following equation:

$$
\text { Relative Price } \mathrm{t}=\alpha+\beta_{1} \mathrm{FW}_{\mathrm{t}}+\beta_{2} \text { Coles }_{\mathrm{t}}+\varepsilon_{\mathrm{t}}
$$

where

Relative Price $_{\mathrm{t}}=$ Average Price $_{\text {Perth }}-$ Average Price $_{\text {Eastern Capitals }}$ at time $\mathrm{t}$ $\alpha=$ a constant representing the average Relative Price before the FuelWatch scheme was introduced

$\beta_{1}=$ the average impact of the FuelWatch scheme

$\mathrm{FW}_{\mathrm{t}}=1$ after 2 January 2001 and $=0$ before 2 January 2001

$\beta_{2}=$ the average impact of the entry of Coles

Coles $_{\mathrm{t}}$ is a dummy variable $=1$ after March 2004 and $=0$ before March 2004

Consistent with the ACCC analysis, I use the time period August 1998 to June 2007 for the empirical analysis. Results are shown in Table 2.

Table 2: FuelWatch and Coles structural break test for relative prices (August 1998-June 2007).

\begin{tabular}{lccccccc}
\hline & \multicolumn{2}{c}{ Constant } & \multicolumn{2}{c}{ FuelWatch } & \multicolumn{2}{c}{ Coles } & Adj-R $^{2}$ \\
\hline Weekly Average & 3.0246 & $(0.0000)$ & 0.0121 & $(0.9562)$ & -1.7403 & $(0.0000)$ & 0.2137 \\
Monthly Average & 3.0207 & $(0.0000)$ & 0.0024 & $(0.9931)$ & -1.7077 & $(0.0000)$ & 0.3890 \\
\hline
\end{tabular}

Numbers in parenthesis are p-values. Standard errors are Newey-West corrected.

The results are now very different from the ACCC analysis. The dummy variable associated with FuelWatch is now not statistically significant. The Coles variable is highly statistically significant and indicates that greater competition in the form of Coles entering the market caused the relative price of fuel to fall by about $1.7 \mathrm{cpl}$. In addition, the adjusted $\mathrm{R}^{2}$ are now much higher than before. This result is consistent with the ACCC initial expectation regarding the WA petrol market. As Brian Cassidy told the Senate estimates committee on 5 June 2008: 'At the time, I readily agree with you — I did not actually say it in evidence - my feelings were that it was probably the entry of Coles that had the major impact on prices in WA, but I have been subsequently proven wrong' (Senate Estimates Hansard, 5 June 2008: E7). The irony, of course, is that Brian Cassidy 
was not 'proven wrong'; the ACCC did not report any analysis comparing FuelWatch and the entry of Coles into the WA market in its 2007 report. The analysis here supports his initial views.

\section{The Harding Critique: Real Margins not Nominal Margins}

Don Harding of the School of Business at La Trobe University released a comprehensive econometric critique of the ACCC Appendix S analysis (Harding 2008a; 2008b). He argues that the ACCC relied on a nominal price margin when it should have used a real price margin. Specifically, Harding is able to show that once the data are corrected for inflation, it is not possible, based on this data, to say as the ACCC did that the WA FuelWatch scheme did not act to increase the real retail margin for petrol in Perth.'

In the analysis above, like the ACCC, I too have relied on nominal relative prices. Therefore in order to check the robustness of my results I calculate the inflation adjusted average petrol prices in each of the capital cities in constant May 2008 dollars, then recalculate the relative price margin and then re-estimate equations (3) and (4). Consumer Price Index data are published by the Australian Bureau of Statistics on a quarterly basis. I use the quarterly figure for each month within the quarter, but also use the average quarterly petrol price reported by the Australian Automobile Association to provide a further check to the analysis. Results are shown in Table 3.

Table 3: FuelWatch and Coles structural break test for relative prices. Monthly average for the period August 1998-June 2007. Quarterly average for the period Q4 1980-01 2007

\begin{tabular}{lrrrrrrr}
\hline & \multicolumn{2}{c}{ Constant } & \multicolumn{2}{c}{ FuelWatch } & \multicolumn{2}{c}{ Coles } & Adj-R $^{2}$ \\
\hline Monthly Average & 5.4407 & $(0.0000)$ & -0.8041 & $(0.0869)$ & & & 0.0268 \\
Monthly Average & 5.4407 & $(0.0000)$ & 0.6184 & $(0.0967)$ & -2.8451 & $(0.0000)$ & 0.4641 \\
Quarterly Average & 4.8883 & $(0.0000)$ & -0.7123 & $(0.5388)$ & & & 0.0003 \\
Quarterly Average & 4.8883 & $(0.0000)$ & 1.2154 & $(0.1829)$ & -3.7072 & $(0.0000)$ & 0.0801 \\
\hline
\end{tabular}

Numbers in parenthesis are p-values. Standard errors are Newey-West corrected.

Overall, the results are consistent with my previous analysis. The introduction of the FuelWatch scheme into WA had a small effect, if any, while the arrival of Coles had a large effect on petrol prices in Perth relative to the eastern states. It is worth noting that in two of the equations the FuelWatch coefficient is positive (although only statistically significant in one instance), which indicates that, everything else being equal, FuelWatch actually caused prices to rise in Perth relative to the eastern capitals. Not too much should be made of that result, however, as the significance level $(\mathrm{p}=0.0967)$ is very poor.

The net result of the empirical analysis I have conducted is that the ACCC has underestimated the impact of the Coles entry into the WA market. What is particularly troubling is that the ACCC did not report any analysis along these 
lines in their 2007 report, although they assure the Senate Estimates committee that (a) they had undertaken that analysis and (b) that the Coles effect was small. I have argued the Coles effect is not small and it dominates the FuelWatch effect.

\section{Margins Reduced Everywhere!}

The ACCC investigated the differential between Perth and eastern capital cities and found that FuelWatch had reduced the price differential. In this section I argue against that conclusion by reductio ad absurdum.

I calculate, using the weekly Informed Sources price data, the differential between Sydney and Melbourne and subject that price differential to the ACCC test; that is, the introduction of FuelWatch to WA, and also the introduction of Coles into WA. Results are shown in Table 4.

Table 4: FuelWatch and Coles structural break test for relative prices (August

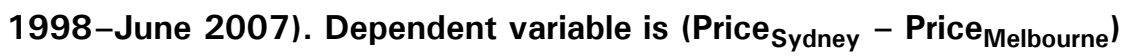

\begin{tabular}{|c|c|c|c|c|c|c|c|}
\hline \multirow[b]{2}{*}{ Weekly Average } & \multicolumn{2}{|c|}{ Constant } & \multicolumn{2}{|c|}{ FuelWatch } & \multicolumn{2}{|c|}{ Coles } & \multirow{2}{*}{$\begin{array}{c}\text { Adj-R }^{2} \\
0.0579\end{array}$} \\
\hline & 1.6786 & $(0.0000)$ & -1.0446 & $(0.0002)$ & & & \\
\hline Weekly Average & 1.6786 & $(0.0000)$ & -1.1809 & $(0.0003)$ & 0.2742 & $(0.4521)$ & 0.0567 \\
\hline
\end{tabular}

Numbers in parenthesis are p-values. Standard errors are Newey-West corrected.

The ACCC-type test tells us that the introduction of FuelWatch into the WA market had the effect of reducing the petrol price differential between Sydney and Melbourne. That result is clearly absurd. It is pleasing, however, that the entry by Coles into the WA market had no effect on the Sydney-Melbourne price differential. That, of course, is the result that we would expect.

\section{Consumer Empowerment?}

The ACCC subsequently shifted the policy goalposts to arguing that saving a few cents per litre was not the objective of the policy at all. According to Graeme Samuel: 'It is not about 1.9c or 0.7c or whatever econometric modelling might be able to show' (Senate Estimates Hansard, 5 June 2008: E16); rather the FuelWatch scheme would empower consumers. Graeme Samuel has described FuelWatch as 'a consumer empowerment exercise. It is designed to empower consumers to take advantage of a competitive marketplace (Ibid).

We are invited to believe that fixing prices constitutes a 'competitive marketplace'. This is, of course, entirely counterintuitive. As Chris Bowen wrote in the Sydney Morning Herald: 'I was intrigued that the body whose charter is to promote competition in Australia was telling Australia's first Competition Minister that a scheme to limit changes in petrol prices should now be considered to promote competition in the fuel market' (SMH, 4 June 2008; emphasis added). Chris Bowen's scepticism was well-placed and we know that he was convinced by the ACCC's econometric analysis that has been critiqued above. In essence, the ACCC was trading off fixed prices against asymmetric information. The difficulty the 
ACCC have is that it did not say how big the asymmetric information problem is in the petrol market, nor do the ACCC provide any argument or evidence to suggest that the economic gains from reducing asymmetric information are greater than the economic costs of price fixing. Asymmetric information is a theoretical problem - in the real world markets evolve solutions to deal with that problem (albeit imperfectly). By contrast, price fixing is a real-world problem. So much so that price fixing is illegal under the Trade Practices Act. After much prompting by Senator Helen Coonan, the ACCC admitted that if petrol retailers colluded to create their own FuelWatch-type scheme whereby prices were fixed for 24 hours 'then that is rather more likely to be a breach of the Trade Practices Act' (Senate Estimates, 5 June 2008: E81).

\section{Conclusion}

The ACCC has not produced a rigorous assessment of FuelWatch. Furthermore, the ACCC discouraged external assessment of their analysis. It made use of 'secret data', 'secret econometric tests', 'secret analysis', and 'secret recommendations' to government to propose a national FuelWatch scheme. Ultimately, the Australian population are being invited to believe that the national adoption of FuelWatch is good public policy simply because the ACCC asserts it to be good policy. Yet there is no corroborating evidence to support the ACCC's assertion. Indeed, all the empirical evidence in the public domain rejects the ACCC's position.

We argue FuelWatch will reduce the level of price competition in the petrol market. The present significant degree of price competition in the retail petrol market is likely to be translated into non-price competition. Non-price competition is likely to make petrol pricing less transparent rather than more transparent. That loss in transparency disadvantages those consumers who would prefer a lower price to an enhanced Loyalty Scheme. Thus, the unintended consequences of the FuelWatch scheme will be to increase existing barriers to entry, increase market power of existing retailers, and disadvantage those consumers who buy their petrol at the bottom of the pricing cycle. In order to protect the 'integrity' of the FuelWatch system, the ACCC would have to prohibit competition for petrol in both pricing and promotional terms. This highlights the fundamental problem with FuelWatch.

\section{References}

Australian Competition \& Consumer Commission 2002, Terminal gate pricing arrangements in Australia and other fuel pricing arrangements in Western Australia, December. Available at: www.accc.gov.au

Australian Competition \& Consumer Commission 2007, Petrol Prices and Australian Consumers: Report of the ACCC into unleaded petrol, December. Available at: www.accc.gov.au 
Australian Competition \& Consumer Commission 2008, ACCC Issues Details of Further Fuelwatch Econometric Analysis, Press release, May. Available at: www.accc.gov.au

Harding, Don 2008a, Fool Watch: A case study of econometric analysis and 'evidence-based-policy making' in the Australian government, submission to Senate inquiry. Available at: www.aph.gov.au/Senate/committee/ economics_ctte/fuelwatch_08/submissions/sub04_attach_A.pdf

Harding, Don 2008b Fool Watch — Further discussion of econometric analysis undertaken by $A C C C$, July. Submission to Senate inquiry, available at: www.aph.gov.au/Senate/committee/economics_ctte/fuelwatch_08/submissions/ sub04_attach_B.pdf 